\title{
ОСАДКООБРАЗОВАНИЕ НА АНИОНООБМЕННОЙ МЕМБРАНЕ МА-40 ПРИ ЭЛЕКТРОДИАЛИЗЕ СИЛЬНОМИНЕРАЛИЗОВАННЫХ ПРИРОДНЫХ ВОД
}

\author{
(C) 2017 Э. М. Акберова, А. М. Яцев, Е. А. Голева, В. И. Васильева \\ Воронежский государственный университет, Университетская пл., 1, 394018 Воронеж, Россия \\ e-mail: elmara_09@inbox.ru
}

Поступила в редакцию 10.05.2017 г.

\begin{abstract}
Аннотация. Проведена оценка влияния структурных изменений анионообменной мембраны MA-40 после длительной эксплуатации в электродиализаторах различного типа на ее физикохимические и электрохимические свойства. Основными причинами ухудшения транспортных свойств образцов мембран являются осадкообразование на поверхности и в объеме мембраны, а также деструкция ионогенных групп мембран. Установлен состав минеральных отложений, образовавшихся в процессе эксплуатации анионообменной мембраны при деминерализации и концентрировании природных вод.
\end{abstract}

Ключевые слова: анионообменная мембрана, реверсный электродиализатор, электродиализатор-концентратор, природные воды, осадкообразование.

\section{ВВЕДЕНИЕ}

Для производства чистой воды используется множество методов, например, дистилляция, электродиализ, вымораживание, обратный осмос и т.д. Современные мембранные методы позволяют получать очищенную воду практически из любых природных источников, как артезианских, так и поверхностных. Электродиализ все еще остается наиболее важным методом обессоливания воды, хотя в большей мере применяется обратный осмос или гибридные методы [1].

Главным ограничением, ухудшающим эффективность электродиализа при деминерализации природных вод, является снижение электрохимической активности мембран под воздействием поляризационных и температурных эффектов, а также осадкообразования [2]. Выпадение в осадок на поверхности и в объеме мембран труднорастворимых солей и гидроксидов значительно ухудшает их эксплуатационные характеристики, экранирует поверхность мембран и приводит к прекращению переноса электрического тока [3-8].

В связи с этим перед электродиализом природных вод применяют либо умягчение катионным обменом, заменяющим катионы солей жесткости катионами натрия, либо периодически изменяют направление постоянного электрического тока (реверсивный электродиализ), что меняет функции секций обессоливания и концентрирования и приводит к растворению осадков на поверхности ионообменных мембран $[9,10]$. Процесс реверсивного электродиализа (ЭДР) успешно применяется для опреснения слабоминерализованных вод [11-14], так как обеспечивает их эффективное обессоливание при минимальной предочистке и низких эксплуатационных затратах. В настоящее время тысячи установок реверсивного электродиализа действуют в различных областях: при опреснении солоноватых вод для получения питьевой воды и концентрировании минеральных солей из сточных вод для повторного использования в промышленности и сельском хозяйстве. Недостатки - периодичность процесса, сложность аппаратурного оформления и увеличение затрат на изготовление электродов из благородных металлов, например, платины.

Осадкообразование на мембранах - сложный и неоднозначный процесс, теоретическое моделирование которого затруднено из-за многофакторности причин. Поэтому изменения свойств и снижение производительности мембран во время эксплуатации определяют экспериментально $[15,16]$.

Физико-химические свойства и транспортные характеристики ионообменных мембран находятся в непосредственной связи с их структурой. Влия- 
ние воздействия тока и температуры в ходе электродиализа на электрохимические и структурные свойства, приводящее к необратимым изменениям в мембранах, отмечалось в [17-27].

Цель настоящей работы - выявление взаимосвязи между структурными и транспортными характеристиками анионообменной мембраны МА-40 после длительной эксплуатации при обессоливании и концентрировании природных вод.

\section{ЭКСПЕРИМЕНТАЛЬНАЯ ЧАСТЬ}

В качестве объектов исследования были выбраны образцы выпускаемой ООО ИП «Щекиноазот» анионообменной мембраны MA-40, проработавшие длительное время в электродиализаторе реверсного типа при обессоливании и в аппаратеконцентраторе при концентрировании природных вод. Гетерогенная мембрана МА-40 изготавливается вальцовкой из композиции дисперсного ионообменника и полиэтилена низкого давления при последующем горячем прессовании листов с армирующей тканью (капрон) при температуре $140{ }^{\circ} \mathrm{C}$ и давлении 250 атм. Активный компонент мембраны MA-40 - полифункциональный анионит смешанной основности ЭДЭ-10П, который является продуктом поликонденсации полиэтиленполиамина с эпихлоргидрином и содержит в своем составе третичные и вторичные аминогруппы. В состав мембраны МА-40 могут входить и высокоосновные группы четвертичного аммониевого основания в количестве, достигающем 20 \% [28]. Один образец мембраны для исследований был извлечен после 1000 часов работы из приэлектродной секции реверсного электродиализного аппарата, используемого для обессоливания природных вод Аральского региона, а второй образец - после 500 часов работы при плотности тока $2.5 \mathrm{~A} /$ дм² $^{2}$ из рабочего пакета аппарата-концентратора при получении рассолов с общим солесодержанием 180-200 г/дм ${ }^{3}$ из природных вод Тюменской области. Ресурсные испытания проведены АО «Мембранные технологии», им же предоставлены образцы для исследований.

Одним из важных факторов, влияющих на эффективность электродиализных систем водоподготовки, является качество воды. Химический состав природных вод Аральского региона и Тюменской области представлен в табл. 1. Исходные воды классифицируются как сильноминерализованные, солоноватые, очень жесткие и относятся к хлоридному классу, натриевой группе.

Современные электродиализаторы основаны на принципе чередования катионообменных и анионообменных мембран в многосекционных аппаратах, где число секций достигает несколько сотен. На рис. 1 представлена принципиальная схема семисекционного электродиализатора с чередующимися катионообменными и анионообменными мембранами. При наложении разности электрического потенциала положительно заряженные ионы мигрируют к катоду, а отрицательно заряженные ионы - к аноду. При этом анионы не могут проходить через отрицательно заряженные катионообменные мембраны, а катионы - через положительно заряженные анионообменные мембраны. Общим результатом процесса является увеличение концентрации ионов в нечетных камерах (секции концентрирования) при одновременном уменьшении их концентрации в четных камерах (секции обессоливания). На электродах осуществляется электролиз: на отрицательно заряженном катоде продуктами электролиза являются газо-

Таблица 1. Химический состав природных вод Аральского региона и Тюменской области

[Table 1. Chemical composition of natural waters of the Aral region and the Tyumen region]

\begin{tabular}{|c|c|c|c|c|}
\hline \multirow{2}{*}{$\begin{array}{l}\text { Компонент } \\
\text { [Component] }\end{array}$} & \multicolumn{2}{|c|}{$\begin{array}{c}\text { Аральский регион } \\
\text { [Aral region] }\end{array}$} & \multicolumn{2}{|c|}{$\begin{array}{c}\text { Тюменская область } \\
\text { [Tyumen region] }\end{array}$} \\
\hline & $\begin{array}{c}\mathrm{мг} / д м^{3} \\
{\left[\mathrm{mg} / \mathrm{dm}^{3}\right]} \\
\end{array}$ & $\begin{array}{c}\text { ммоль/дм } \\
{\left[\mathrm{mmol} / \mathrm{dm}^{3}\right]}\end{array}$ & $\begin{array}{c}\mathrm{мг} / \text { дм }^{3} \\
{\left[\mathrm{mg} / \mathrm{dm}^{3}\right]}\end{array}$ & $\begin{array}{c}\text { ммоль/дм' } \\
{\left[\mathrm{mmol} / \mathrm{dm}^{3}\right]}\end{array}$ \\
\hline Натрий [Sodium] & 3911 & 170.0 & 5732 & 249.2 \\
\hline Кальций [Calcium] & 313 & 7.8 & 407 & 10.2 \\
\hline Магний [Magnesium] & 400 & 16.7 & 381 & 15.8 \\
\hline Калий [Potassium] & 23 & 0.6 & - & - \\
\hline Гидрокарбонаты [Hydrocarbonates] & 183 & 3.0 & 189 & 3.1 \\
\hline Хлориды [Chlorides] & 6671 & 188.0 & 10582 & 298.1 \\
\hline Сульфаты [Sulphates] & 1368 & 14.2 & - & - \\
\hline Общее солесодержание [Total salt content] & 12870 & & 17290 & \\
\hline Жесткость, мг-экв/дм³ [Hardness, mg-equ/dm³] & \multicolumn{2}{|c|}{49} & \multicolumn{2}{|c|}{52} \\
\hline $\mathrm{pH}$ & \multicolumn{2}{|c|}{7.5} & \multicolumn{2}{|c|}{7.3} \\
\hline
\end{tabular}




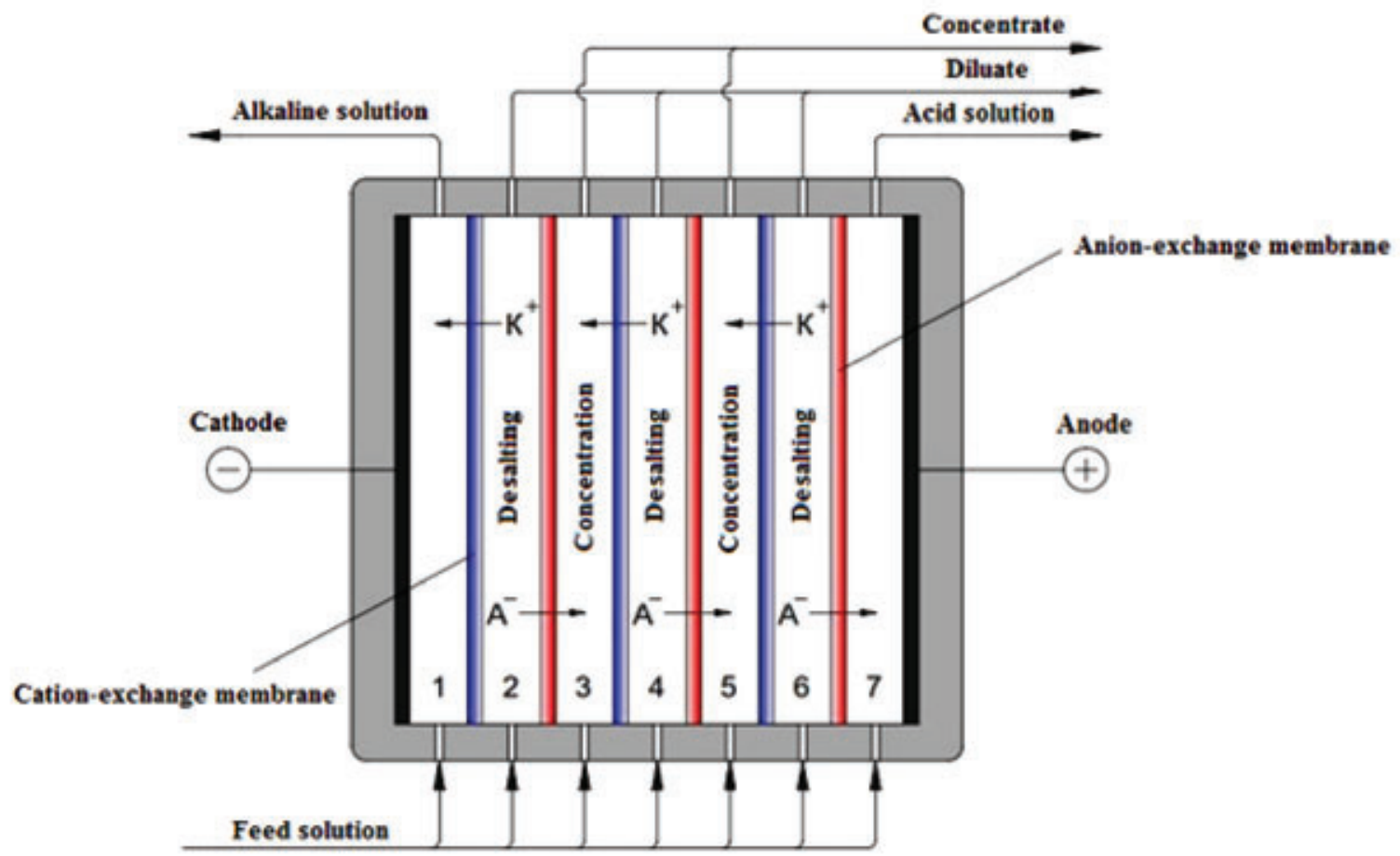

Рис. 1. Схема установки реверсного электродиализатора

[Fig. 1.Scheme of the reverse electrodialysis stack]

образный водород и гидроксид-ионы (1), а на положительно заряженном аноде выделяются газообразные хлор (2), кислород и ионы водорода (3):

$$
\begin{gathered}
2 \mathrm{H}_{2} \mathrm{O}+2 \mathrm{e} \rightarrow \mathrm{H}_{2} \uparrow+2 \mathrm{OH}^{-}, \\
2 \mathrm{Cl}^{-}-2 \mathrm{e} \rightarrow \mathrm{Cl}_{2} \uparrow, \\
2 \mathrm{H}_{2} \mathrm{O}-4 \mathrm{e} \rightarrow \mathrm{O}_{2} \uparrow+4 \mathrm{H}^{+} .
\end{gathered}
$$

Таким образом, в катодной камере образуется щелочной раствор католита, а в анодной - кислый раствор анолита.

Принцип действия метода ЭДР состоит в изменении направления течения тока с одновременным изменением направления потоков жидкости так, чтобы камеры обессоливания превращались в камеры концентрирования и наоборот. Во время проведения процесса направление потоков и полярность меняются каждые 30 минут. При переполюсовке электродов задается то же или половинное значение тока.

Физико-химические, транспортные и структурные характеристики мембран после эксплуатации сравнивали с образцами мембраны МА-40, кондиционированными по стандартным методикам [29].

Интегральный коэффициент диффузионной проницаемости мембран определяли методом оценки количества электролита, перенесенного из раствора соли заданной концентрации под влиянием диффузионных сил через исследуемую мембрану в чистую воду [30]. Для измерения удельной электро- проводности был применен контактно-разностный метод [31], заключающийся в измерении импедансов одной и двух мембран в ячейке с платиновыми электродами и нахождении их векторной разности, которую рассматривали как истинное электросопротивление мембраны.

Морфологию поверхности сухих и набухших образцов мембран исследовали методом сканирующей электронной микроскопии (СЭМ) на приборе JSM-6380 LV (Япония), оснащенном энергодисперсионным анализатором элементного состава и регулятором давления в камере с исследуемым образцом. Количественная оценка доли и размеров макропор на поверхности мембран проводилась с помощью авторского программного комплекса [32].

\section{РЕЗУЛЬТАТЫ И ИХ ОБСУЖДЕНИЕ}

Сравнение основных физико-химических характеристик образцов анионообменной мембраны МА-40 после химического кондиционирования и эксплуатации в электродной секции реверсного электродиализатора и рабочем пакете аппаратаконцентратора представлено в табл. 2. Мембраны, расположенные в электродных секциях, работают в наиболее жестких условиях, поскольку в этом случае они непосредственно соприкасаются с продуктами, образующимися по реакциям (1-3) при электролизе минерализованной воды. Для мембраны 
Таблица 2. Физико-химические характеристики набухших образцов анионообменной мембраны МА-40 после кондиционирования, работы в реверсном электродиализаторе и электродиализаторе-концентраторе

[Table 2. Physical-chemical characteristics of swollen samples of the MA-40 anion-exchange membrane after conditioning, use in the reverse electrodialysis stack and electrodialyzer-concentrator]

\begin{tabular}{|c|c|c|c|c|}
\hline $\begin{array}{l}\text { Образец мембраны } \\
\text { [Membrane sample] }\end{array}$ & $\begin{array}{c}Q, \text { ммоль/Г } \\
{[Q, \mathrm{mmol} / \mathrm{g}]}\end{array}$ & $\begin{array}{c}\text { Влагосодержание } W, \% \\
\text { [Water content } W, \%]\end{array}$ & $\begin{array}{l}\text { Толщина, мкм } \\
\text { [Thickness, } \mu \mathrm{m}]\end{array}$ & 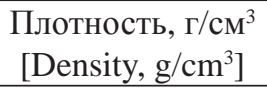 \\
\hline $\begin{array}{c}\text { Кондиционированный } \\
\text { [Conditioned] }\end{array}$ & $2.71 \pm 0.09$ & $38 \pm 3$ & $560 \pm 20$ & 1.19 \\
\hline $\begin{array}{c}\text { Аппарат-концентратор } \\
\text { [Electrodialyzer-concentrator] }\end{array}$ & $2.47 \pm 0.09$ & $43 \pm 2$ & $580 \pm 10$ & 1.10 \\
\hline $\begin{array}{c}\text { Реверсный электродиализатор } \\
\text { [Reverse electrodialysis stack] }\end{array}$ & $2.20 \pm 0.08$ & $35 \pm 1$ & $505 \pm 5$ & 1.20 \\
\hline
\end{tabular}

МА-40 из приэлектродной секции реверсного электродиализатора установлено уменьшение полной обменной емкости, влагосодержания и толщины. Потеря полной обменной емкости мембран связана с потенциальной возможностью протекания процессов термодеструкции ионообменного материала [26, 27, 33]. При нагревании в воде происходят реакции дезаминирования с отщеплением от полимерной матрицы четвертичного амина:

$$
\begin{aligned}
& \mathrm{C}_{6} \mathrm{H}_{5} \mathrm{CH}_{2} \mathrm{~N}\left(\mathrm{CH}_{3}\right)_{3} \mathrm{OH}+\mathrm{H}_{2} \mathrm{O} \stackrel{t^{\circ}}{\rightarrow} \\
& \rightarrow \mathrm{C}_{6} \mathrm{H}_{5} \mathrm{CH}_{2} \mathrm{OH}+\mathrm{NH}\left(\mathrm{CH}_{3}\right)_{3} \mathrm{OH}
\end{aligned}
$$

и деградации с образованием третичных аминогрупп

$$
\begin{aligned}
& \mathrm{C}_{6} \mathrm{H}_{5} \mathrm{CH}_{2} \mathrm{~N}\left(\mathrm{CH}_{3}\right)_{3} \mathrm{OH}+\mathrm{H}_{2} \mathrm{O} \stackrel{t^{\circ}}{\rightarrow} \\
\rightarrow & \mathrm{C}_{6} \mathrm{H}_{5} \mathrm{CH}_{2} \mathrm{NH}\left(\mathrm{CH}_{3}\right)_{2} \mathrm{OH}+\mathrm{CH}_{3} \mathrm{OH},
\end{aligned}
$$

которые затем могут трансформироваться во вторичные аминогруппы:

$$
\begin{gathered}
\mathrm{C}_{6} \mathrm{H}_{5} \mathrm{CH}_{2} \mathrm{NH}\left(\mathrm{CH}_{3}\right)_{2} \mathrm{OH}+\mathrm{NH}\left(\mathrm{CH}_{3}\right)_{3} \mathrm{OH} \stackrel{t^{\circ}}{\rightarrow} \\
\rightarrow \mathrm{C}_{6} \mathrm{H}_{5} \mathrm{CH}_{2} \mathrm{NH}_{2} \mathrm{CH}_{3} \mathrm{OH}+\mathrm{N}\left(\mathrm{CH}_{3}\right)_{4} \mathrm{OH} .
\end{gathered}
$$

Исследование транспортных характеристик мембран МА-40 показало, что по сравнению с кондиционированным образцом длительная эксплуатация в реверсном электродиализаторе привела к уменьшению не только удельной электропроводности, но и диффузионной проницаемости (рис. 2).
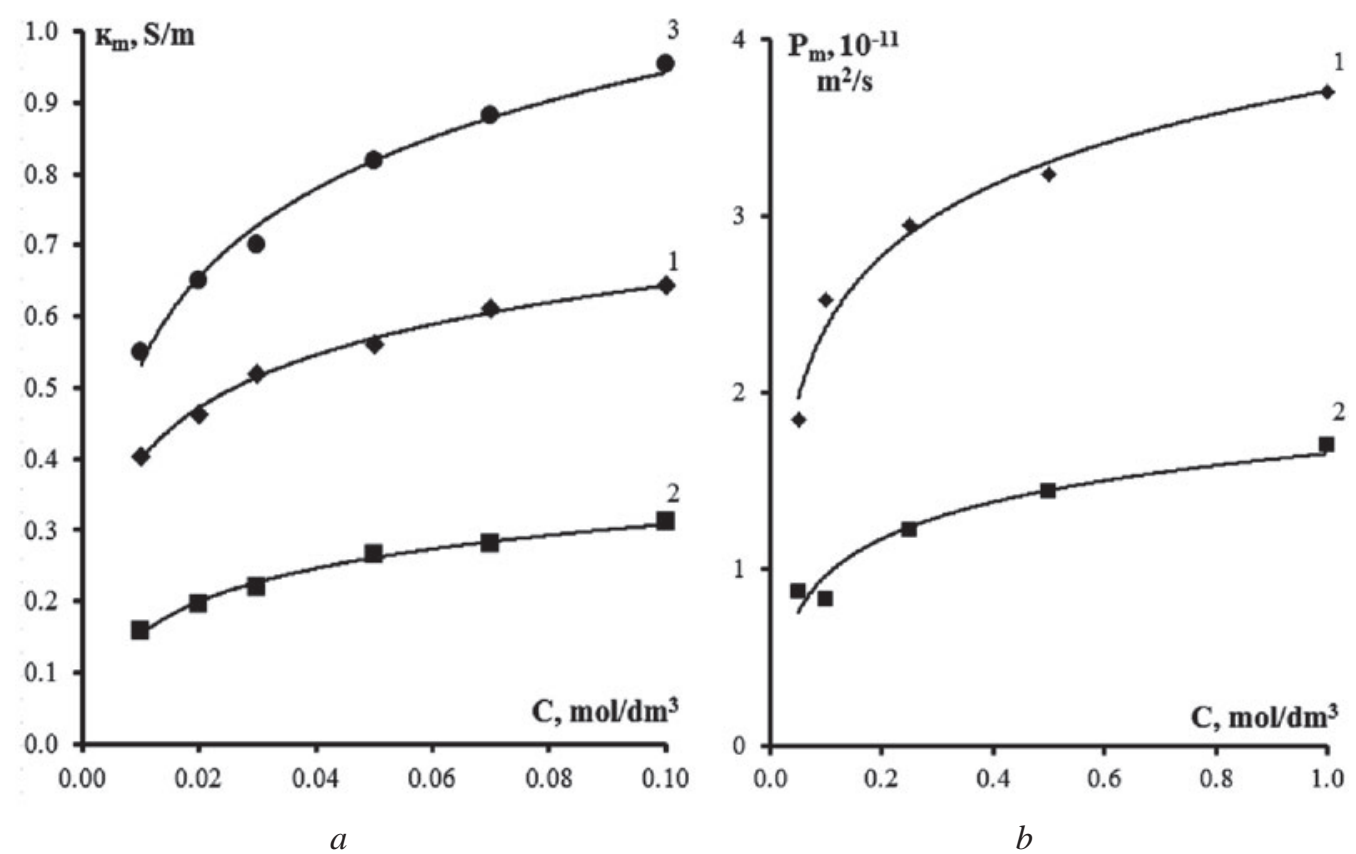

Рис. 2. Концентрационные зависимости удельной электропроводности $(a)$ и диффузионной проницаемости $(b)$ кондиционированного (1) образца мембраны МА-40, из приэлектродной секции реверсного электродиализного аппарата (2), из рабочего пакета аппарата-концентратора (3)

[Fig. 2. Concentration dependencies of the specific electrical conductivity $(a)$ and diffusion permeability $(b)$ of the conditioned (1) sample of the MA-40 membrane, the sample from the near-electrode section of the reverse electrodialysis stack (2), the sample from the operating package of the concentrator apparatus (3)] 
Данный факт обусловлен тем, что в процессе работы этих образцов мембран произошла не только деструкция ионогенных групп вследствие воздействия продуктов электролиза и перегрева, а также значительные изменения микроструктуры их поверхности и объема, связанные с образованием минеральных отложений.

При электродиализном опреснении природных соленых и солоноватых вод образующиеся на по- верхности мембран осадки состоят, в основном, из карбоната и сульфата кальция и гидроксидов магния, кальция и железа. Предполагаемый состав и рассчитанные величины рН начала осаждения малорастворимых соединений представлены в табл. 3.

Электронно-микроскопические изображения отдающей поверхности 2 образца мембраны МА-40 из приэлектродной секции реверсного электродиализатора представлены на рис. 3. В анодной сек-

Таблица 3. Состав, константы растворимости $K_{\mathrm{s}}$ и $\mathrm{pH}$ начала осаждения предполагаемых нерастворимых соединений, образующихся на поверхности и в объеме мембраны MA-40

[Table 3. Composition, solubility constants $K_{\mathrm{s}}$ and $\mathrm{pH}$ of the beginning of precipitation of supposed insoluble compounds formed on the surface and in the bulk of the MA-40 membrane]

\begin{tabular}{|c|c|c|}
\hline $\begin{array}{c}\text { Состав осадка } \\
\text { [Composition of the mineral deposit] }\end{array}$ & $K_{\mathrm{s}}[34]$ & $\mathrm{pH}$ \\
\hline $\mathrm{CaSO}_{4}$ & $9.1 \cdot 10^{-6}$ & - \\
\hline $\mathrm{CaCO}_{3}$ & $4.8 \cdot 10^{-9}$ & 6.63 \\
\hline $\mathrm{Mg}(\mathrm{OH})_{2}$ & $1.8 \cdot 10^{-11}$ & 9.52 \\
\hline $\mathrm{MgCO}_{3}$ & $2.1 \cdot 10^{-5}$ & 9.94 \\
\hline $\mathrm{Ca}(\mathrm{OH})_{2}$ & $5.5 \cdot 10^{-6}$ & 11.56 \\
\hline $\mathrm{Fe}(\mathrm{OH})_{3}$ & $3.2 \cdot 10^{-38}$ & - \\
\hline
\end{tabular}

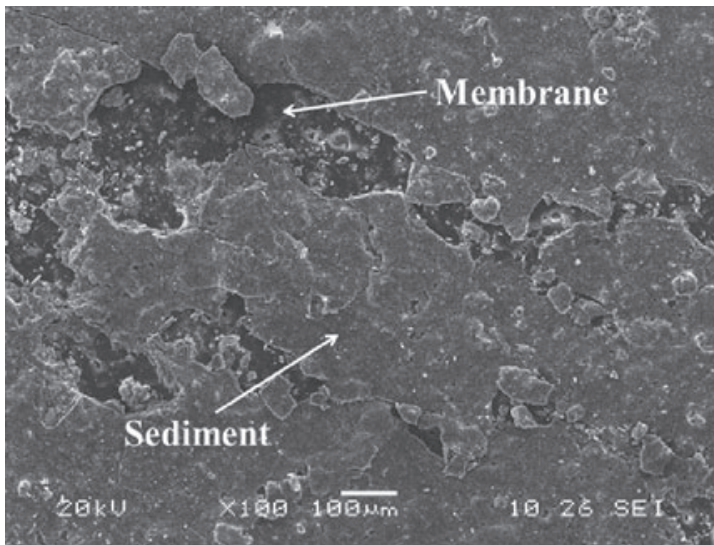

a

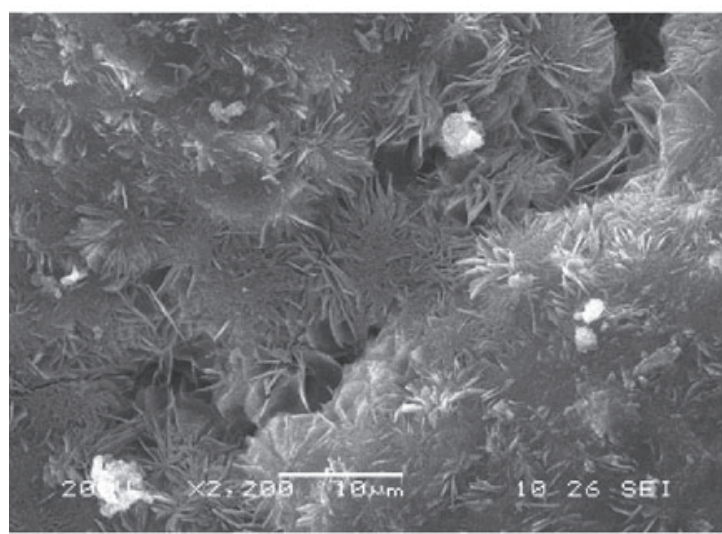

C

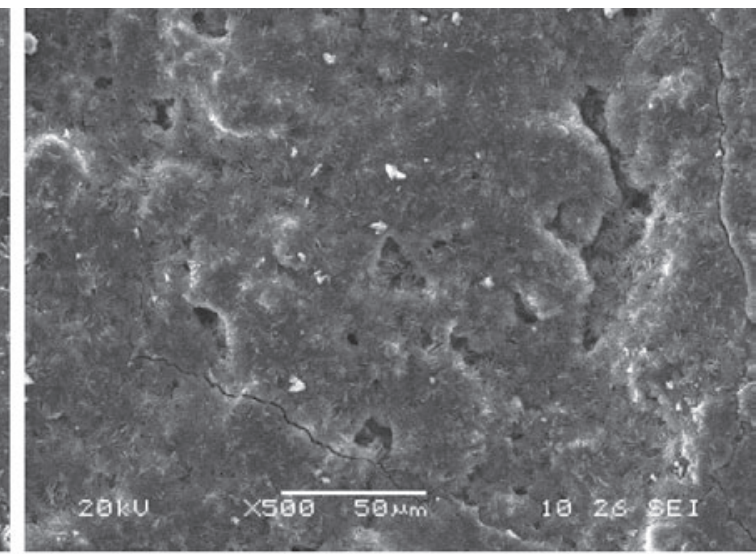

$b$

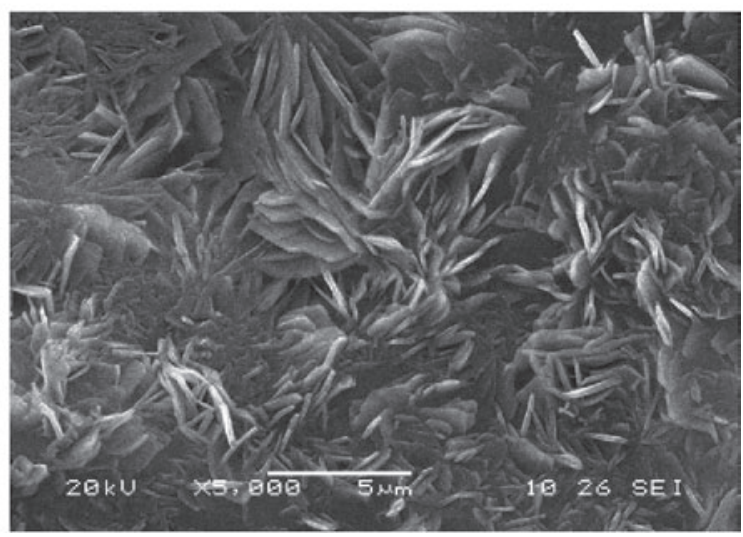

d

Рис. 3. СЭМ-изображения отдающей поверхности 2 сухого образца мембраны МА-40 из приэлектродной секции реверсного электродиализатора при увеличении $100(a), 500(b), 2200(c), 5000(d)$

[Fig. 3. SEM images of the giving surface 2 of the dry sample of the MA-40 membrane from the near-electrode section of the reverse electrodialysis stack at $\times 100(a), \times 500(b), \times 2200(c), \times 5000(d)$ magnification] 
ции согласно электрохимическим процессам (2, 3) предполагается кислая реакция среды, что гарантирует предотвращение осадкообразования. Однако визуально можно наблюдать образование осадка на обеих поверхностях мембраны, локализованного не только в областях с хорошей электропроводностью, где находятся частицы ионообменника, а покрывающего пленкой практически всю поверхность.

Композитные рентгеновские карты распределения элементов Са и $\mathrm{Mg}$ по поверхностям анионообменной мембраны МА-40 (рис. 4) и результаты рентгеноспектрального микроанализа компонентного состава осадка (табл. 4) показали преимущественное содержание Mg и присутствие элементов Са и Fе.

Образование осадка гидроксидов является следствием увеличения $\mathrm{pH}$ раствора в примембранной области и секции концентрирования. При превышении предельной плотности тока образовавшиеся вследствие гетеролитической реакции диссоциации воды потоки гидроксильных ионов через анионообменные мембраны приводят к локальному увеличению рН раствора в примембранной области и созданию условий для образования осадков в секции концентрирования. В этом случае у отдающей поверхности анионообменной мембраны МА-40 в электродной секции происходит подщелачивание раствора, а у принимающей поверхности этой мембраны в смежной секции обессоливания - подкисление. Снижение величины $\mathrm{pH}$ пре- пятствует выпадению осадков карбоната кальция и гидроксида магния и кальция.

Осадок гидроксида магния выпадает при условии превышения произведения ионных концентраций величины константы растворимости $\left[\mathrm{Mg}^{2+}\right]\left[\mathrm{OH}^{-}\right]^{2}>1.8 \cdot 10^{-11}$. При электродиализе природной воды Аральского региона с концентрацией ионов магния 16.7 ммоль/дм ${ }^{3}$ это соответствует $\mathrm{pH}>9.52$. Осадок гидроксида кальция при условии $\left[\mathrm{Ca}^{2+}\right]\left[\mathrm{OH}^{-}\right]^{2}>5.5 \cdot 10^{-6}$ и концентрации ионов каль-

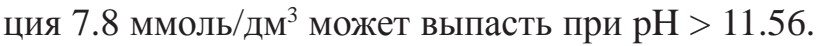
Следует отметить, что в секции концентрирования тенденция к осадкообразованию выше и величина рН начала осаждения гидроксидов несколько ниже в связи с более высокой концентрацией осадкообразующих ионов.

При увеличении рН обрабатываемых растворов возможно также осаждение малорастворимых карбонатов вследствие нарушения углекислотного равновесия в системе [35]:

$$
\begin{gathered}
\mathrm{HCO}_{3}^{-}+\mathrm{H}_{3} \mathrm{O}^{+} \rightarrow \mathrm{H}_{2} \mathrm{CO}_{3} \rightarrow \mathrm{H}_{2} \mathrm{O}+\mathrm{CO}_{2} \uparrow \\
\mathrm{HCO}_{3}^{-}+\mathrm{OH}^{-} \rightarrow \mathrm{H}_{2} \mathrm{O}+\mathrm{CO}_{3}^{2-} .
\end{gathered}
$$

Концентрация карбонатных ионов является функцией концентрации водородных ионов, определяемой величиной константы диссоциации угольной кислоты по второй ступени $K_{2}=4.8 \cdot 10^{-11}$, с учетом условия осаждения карбоната кальция $\left[\mathrm{Ca}^{2+}\right]\left[\mathrm{CO}_{3}^{2-}\right]>\mathrm{K}_{\mathrm{s}}$ величина концентрации водородных ионов, при которой происходит образование карбоната кальция, соответствует:

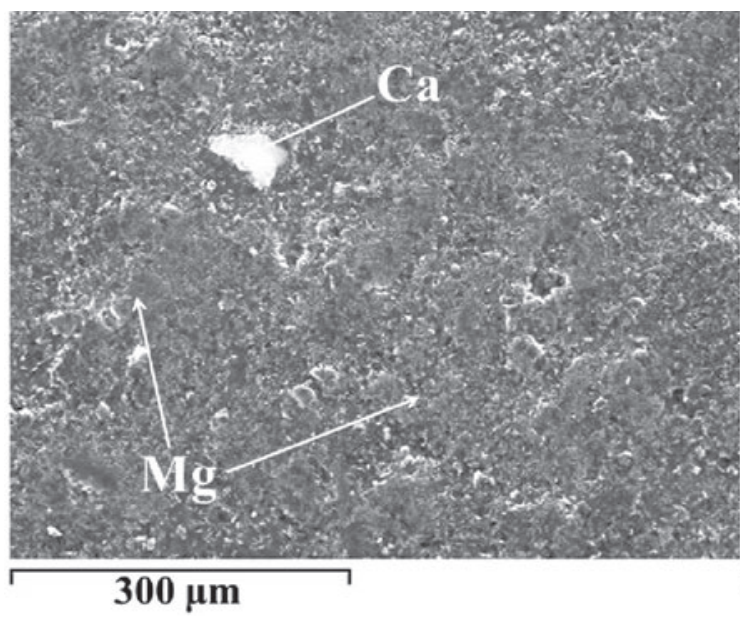

$a$

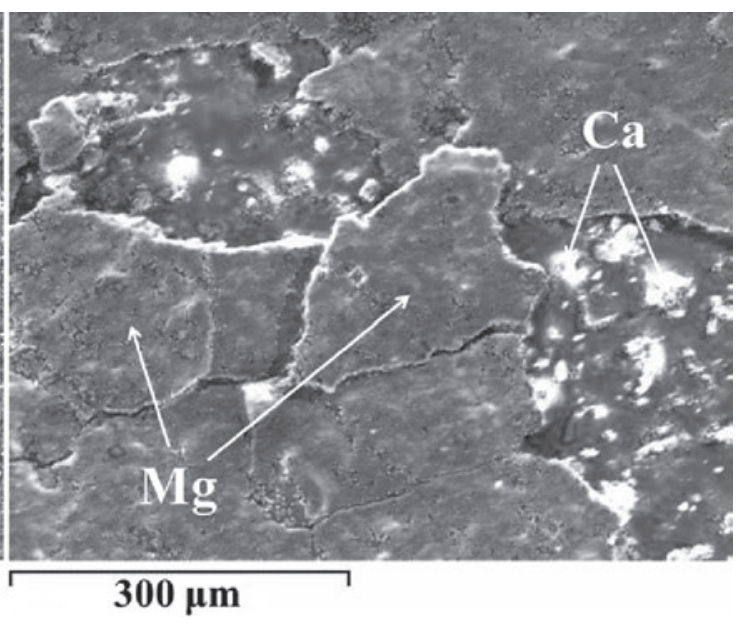

$b$

Рис. 4. Композитные рентгеновские карты распределения Mg (серый цвет) и Са (белый цвет) на принимающей поверхности $1(a)$ и отдающей поверхности $2(b)$ анионообменной мембраны МА-40 из приэлектродной секции реверсного электродиализатора (увеличение 200)

[Fig. 4. Composite X-ray maps of the Mg (gray color) and Ca (white color) distribution on the receiving surface 1 (a) and the giving surface $2(b)$ of the MA-40 anion-exchange membrane from the near-electrode section of the reverse electrodialysis stack (at $\times 200$ magnification)] 


$$
\left[\mathrm{H}_{3} \mathrm{O}^{+}\right]<\frac{\left[\mathrm{Ca}^{2+}\right]\left[\mathrm{HCO}_{3}^{-}\right] \cdot K_{2}}{K_{S}} .
$$

Для концентраций ионов кальция 7.8 ммоль/дм ${ }^{3}$ и гидрокарбонат-ионов 3.0 ммоль/дм³ в очищаемой природной воде рассчитанная по соотношению (9) величина $\mathrm{pH}$ начала осаждения осадка составляет 6.63. Условию образования осадка карбоната магния при его содержании в природной воде 16.7 ммоль/дм ${ }^{3}$ соответствует величина $\mathrm{pH}$, превышающая 9.94.

Следует отметить, что условия образования кристаллических частиц карбонатов кальция и магния в потоке концентрата могут сильно отличаться от условий в исходной природной воде изза увеличения общей концентрации растворенных веществ, нарушения баланса катионов, гидрокарбонатов и свободного $\mathrm{CO}_{2}$.

Изменение $\mathrm{pH}$ растворов не оказывает заметного влияния на процесс образования сульфата кальция, обусловленного достижением и превышением предела его растворимости $\left[\mathrm{Ca}^{2+}\right]\left[\mathrm{SO}_{4}^{2-}\right]>9.1 \cdot 10^{-6}$. Для состава очищаемой воды Аральского региона произведение концентраций ионов кальция и сульфат-ионов составляет $1.1 \cdot 10^{-4}$, что свидетельствует о максимальной возможности выпадения осадка.

Форма изображенных на рис. $3 d$ кристаллов и элементный состав поверхности соответствуют характерным кристаллам гидроксида магния $\mathrm{Mg}(\mathrm{OH})_{2}$. Таким образом, в концентрате электродной секции образуются кристаллы гидроксида магния, которые в сочетании с карбонатом кальция и магния, сульфатом кальция и гидроксидом железа образуют труднорастворимые плотные осадки на поверхности мембран.

Выявлено, что осадкообразование затрагивает не только поверхность, но и объем мембраны. В случае анионообменной мембраны при диссоциации воды на межфазной границе ионы водорода мигрируют в обессоленный раствор, а гидроксидионы - в мембрану. Увеличение $\mathrm{pH}$ внутреннего раствора в мембране способствует осадкообразованию. Сопоставление данных об элементном составе среза (табл. 4) и композитные рентгеновские карты распределения элементов (рис. 5) позволяют сделать вывод о различном содержании и различной локализации осадка по площади сечения. Если на поверхности мембраны преимущественно образуются нерастворимые соединения $\mathrm{Mg}$, то в фазе мембраны с обеих сторон от поверхности установлено образование $\mathrm{CaCO}_{3}$.

Таким образом, снижение электропроводности и полной обменной емкости мембраны МА-40 после эксплуатации в приэлектродной секции реверсного электродиализатора при обессоливании природных вод Аральского региона обусловлено не только трансформацией функционального состава ионообменников, но и блокирующим эффектом вследствие иммобилизации осадка в фазу мембраны. В результате часть ионогенных групп переходит в связанное состояние и не принимает участие в ионном переносе, что приводит к увеличению электрического сопротивления системы. Снижение диффузионной проницаемости и уменьшение

Таблица 4. Элементный состав поверхности и среза образцов мембраны МА-40 (увеличение 200)

[Table 4. Elemental composition of the surface and the cross-section of MA-40 membrane samples (at $\times 200$ magnification)]

\begin{tabular}{|c|c|c|c|c|c|c|c|c|}
\hline \multirow{5}{*}{$\begin{array}{l}\text { Элемент } \\
\text { [Element] }\end{array}$} & \multicolumn{8}{|c|}{$\begin{array}{l}\text { Концентрация, мас. \% } \\
\text { [Concentration, wt. \%] }\end{array}$} \\
\hline & \multicolumn{8}{|c|}{$\begin{array}{l}\text { Образец мембраны } \\
\text { [Membrane sample] }\end{array}$} \\
\hline & \multicolumn{2}{|c|}{$\begin{array}{c}\text { Кондиционированный } \\
\text { [Conditioned] }\end{array}$} & \multicolumn{3}{|c|}{$\begin{array}{l}\text { Концентратор } \\
\text { [Concentrator] }\end{array}$} & \multicolumn{3}{|c|}{$\begin{array}{c}\text { Реверсный электродиализатор } \\
\text { [Reverse electrodialysis stack] }\end{array}$} \\
\hline & \multirow{2}{*}{$\begin{array}{l}\text { Поверхность } \\
\text { [Surface] }\end{array}$} & \multirow{2}{*}{$\begin{array}{l}\text { Cpe3 } \\
{[\text { Cut }]}\end{array}$} & \multicolumn{2}{|c|}{$\begin{array}{l}\text { Поверхность } \\
\text { [Surface] }\end{array}$} & \multirow{2}{*}{$\begin{array}{l}\text { Сpe3 } \\
{[\text { Cut }]}\end{array}$} & \multicolumn{2}{|c|}{$\begin{array}{l}\text { Поверхность } \\
\text { [Surface] }\end{array}$} & \multirow{2}{*}{$\begin{array}{l}\text { Cpe3 } \\
\text { [Cut }]\end{array}$} \\
\hline & & & 1 & 2 & & 1 & 2 & \\
\hline $\mathrm{C}$ & 91.76 & 80.15 & 93.40 & 94.25 & 85.23 & 30.67 & 27.10 & 70.64 \\
\hline $\mathrm{O}$ & 7.62 & 13.89 & 3.38 & 3.44 & 7.83 & 53.69 & 55.83 & 19.02 \\
\hline $\mathrm{S}$ & 0.00 & 5.36 & 0.00 & 0.00 & 0.00 & 0.35 & 0.30 & 0.00 \\
\hline $\mathrm{Ca}$ & 0.00 & 0.00 & 0.05 & 0.04 & 0.12 & 1.98 & 0.48 & 6.86 \\
\hline $\mathrm{Mg}$ & 0.00 & 0.00 & 0.01 & 0.01 & 0.02 & 12.21 & 14.15 & 1.51 \\
\hline $\mathrm{Fe}$ & 0.00 & 0.00 & 0.00 & 0.04 & 0.09 & 0.47 & 1.24 & 0.17 \\
\hline $\mathrm{Si}$ & 0.00 & 0.00 & 0.02 & 0.05 & 0.00 & 0.11 & 0.31 & 0.38 \\
\hline
\end{tabular}




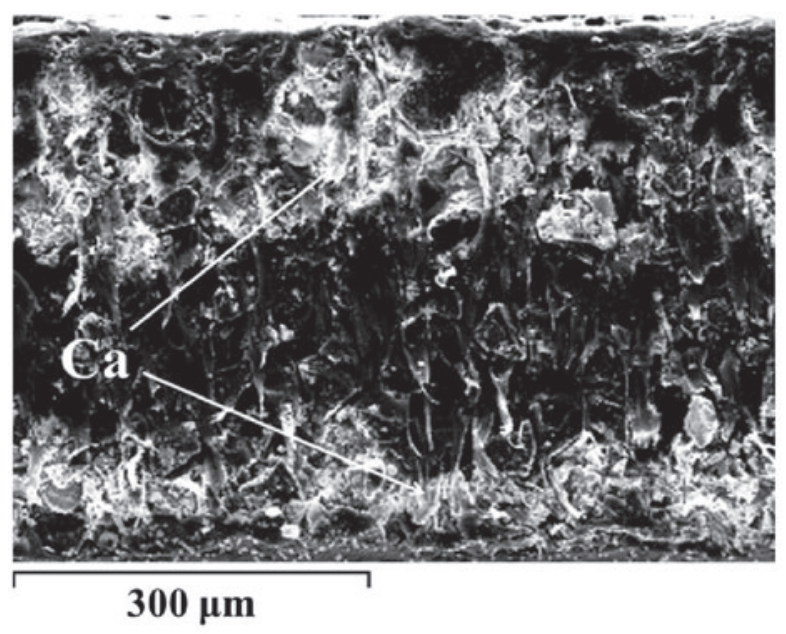

Рис. 5. Композитные рентгеновские карты распределения Са по сечению анионообменной мембраны МА-40 из приэлектродной секций реверсного электродиализатора (увеличение 200)

[Fig. 5. Composite X-ray maps of the Ca distribution on the cross-section of the MA-40 anion-exchange membrane from the near-electrode section of the reverse electrodialysis stack (at $\times 200$ magnification)] размера макропор на поверхности этих образцов (табл. 5) подтверждает факт закупоривания транспортных каналов минеральными осадками.

При изучении транспортных характеристик мембраны МА-40 из рабочего пакета электродиализатора-концентратора были получены результаты, согласно которым удельная электропроводность увеличивается (рис. 2) на фоне потери обменной емкости, роста влагосодержания и толщины мембраны. Результаты количественной оценки порового состава мембран, представленные в табл. 5, свидетельствуют об изменениях микроструктуры, связанных с увеличением макропористости.

Изображения поверхностей мембраны МА-40, полученные методом сканирующей электронной микроскопии, представлены на рис. 6. Минеральные отложения, образовавшиеся в процессе эксплуатации мембраны при концентрировании природных вод Тюменской области, визуально не обнаруживаются. Результаты рентгеноспектрального анализа и рентгеновские карты распределения эле-

Таблица 5. Доля и средневзвешенный радиус макропор на поверхности набухших образцов ионообменной мембраны МА-40

[Table 5. The proportion and weighted average radius of macropores on the surface of swollen samples of the MA-40 ion-exchange membrane]

\begin{tabular}{|c|c|c|}
\hline $\begin{array}{c}\text { Образец мембраны } \\
\text { [Membrane sample] }\end{array}$ & $\begin{array}{c}\text { Пористость } P, \% \\
\text { [Porosity } P, \%]\end{array}$ & $\begin{array}{c}\text { Средневзвешенный радиус } \bar{r}, \text { мкм } \\
\text { [Weighted average radius } \bar{r}, \mu \mathrm{m}]\end{array}$ \\
\hline $\begin{array}{c}\text { Кондиционированный } \\
\text { [Conditioned] }\end{array}$ & $2.2 \pm 0.2$ & 2.53 \\
\hline $\begin{array}{c}\text { Реверсный электродиализатор } \\
\text { [Reverse electrodialysis stack] }\end{array}$ & $2.4 \pm 0.1$ & 2.41 \\
\hline $\begin{array}{c}\text { Концентратор } \\
\text { [Concentrator] }\end{array}$ & $2.8 \pm 0.2$ & 2.90 \\
\hline
\end{tabular}

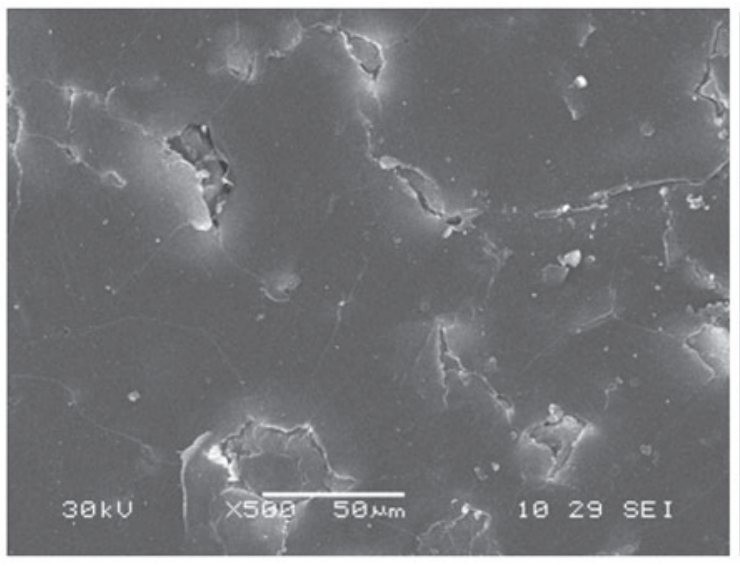

$a$

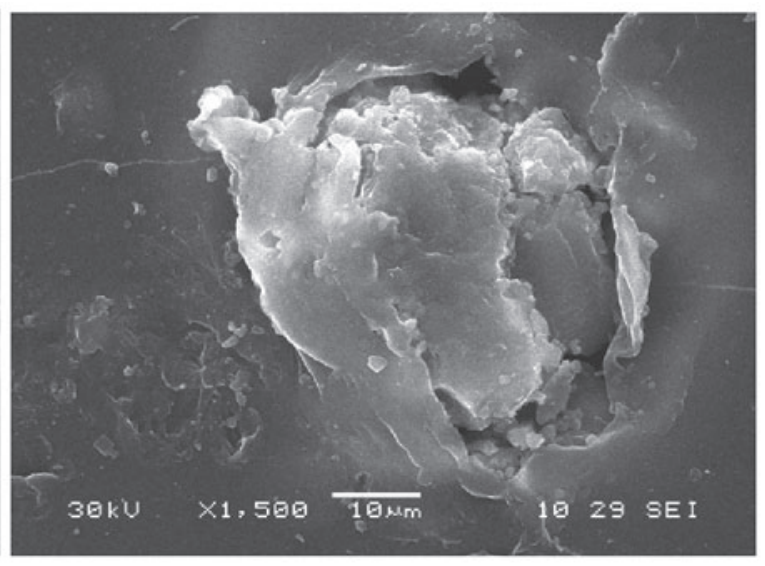

$b$

Рис. 6. СЭМ-изображения поверхности сухого образца мембраны МА-40 из рабочего пакета аппарата-концентратора при увеличении $500(a)$ и $1500(b)$

[Fig. 6. SEM images of the dry sample surface of the MA-40 membrane from the operating package of the concentrator apparatus at $\times 500(a)$ and $\times 1500(b)$ magnification] 
ментов свидетельствуют о незначительном осадкообразовании только в области ионообменных участков на поверхностях мембраны МА-40. Анализ состава концентрируемых природных вод и образующегося осадка показал, что он имеет карбонатную основу.

\section{ЗАКЛЮЧЕНИЕ}

Выявлены различные механизмы снижения эксплуатационных характеристик анионообменной мембраны МА-40 при использовании в процессах деминерализации и концентрирования природных вод методом электродиализа.

Первой и основной причиной ухудшения транспортных свойств мембран из приэлектродных секций реверсного электродиализатора при деминерализации природных вод Аральского региона является осадкообразование, затрагивающее не только поверхность, но и объем мембраны. Образование малорастворимых карбонатов и гидроксидов приводит к блокировке функциональных групп и транспортных каналов мембран, уменьшению электропроводности и затруднению диффузионных процессов. Вторая причина заключается в термодеструкции ионообменного материала.

Главной причиной ухудшения эксплуатационных характеристик анионообменной мембраны MA-40 из мембранного пакета после электродиализного концентрирования природных вод следует выделить деструкцию ионогенных групп мембраны, вызывающую снижение полной обменной емкости. Увеличение макропористости поверхности сопровождалось незначительным осадкообразованием карбонатной природы.

Авторы выражают благодарность директору $A O$ «Мембранные технологии», доктору технических наук, лауреату Государственной премии Казахской ССР в области науки и техники А. А. Цхай за предоставление образиов мембран для исследований.

Микрофотографии поверхности и объема мембран получены в ЦКПНО ВГУ.

Работа выполнена при финансовой поддержке РФФИ (грант № 15-08-05031).

\section{СПИСОК ЛИТЕРАТУРЫ}

1. Мулдер М. Введение в мембранную технологию. М.: Мир, 1999, 513 с.

2. Уилсон Дж. Р. Деминерализаичия методом электродиализа. М.: Госатомиздат, 1963, 351 с.

3. Korngold E., de Körösy F., Rahav R., Taboch M. F. // Desalination, 1970, vol. 8, pp. 195-220.
4. Кастючик А. С., Шапошник В. А. // Сорбционные и хроматографические прочессы, 2009, т. 9, № 1, c. $51-57$.

5. Ивакина Е. И., Шаталов А. Я., Исаев Н. И. Ионообменные мембраны в электродиализе. Ленинград, Химия, 1970, с. 78-84.

6. Бобрешова О. В., Лапшина Т. Е., Шаталов А. Я. // Журнал прикладной химии, 1980, т. 53, № 3, с. 665667.

7. Бобрешова О. В., Шаталов А. Я. // Журнал физической химии, 1977, т. 51, № 1, с. 203-204.

8. Шапошник В. А., Зубец Н. Н., Стрыгина И. П., Милль Б. Е. // Журнал прикладной химии, 2001, т. 74, № 10, c. 1604-1607.

9. Katz W. E. // Desalination, 1979, vol. 28, pp. 31-40.

10. Гребенюк В. Д., Стрижак М. П. // Химия и технология воды, 1985, т. 7, № 5, с. 39-40.

11. Meyer K. H., Straus W. // Helv. Chem. Acta, 1940, vol. 23, pp. 795-800.

12. Гребенюк В. Д., Мазо А. А. Обессоливание воды ионитами. М.: Химия, 1980, 256 с.

13. Gregor H. P., Brunis P. F., Rothenberg M. // Ind. Eng. Chem. Process Des. Dev., 1965, vol. 4, № 1, pp. 3-6.

14. Rozenberg N. W., Tirrell C. E. // Ind. Eng. Chem. Process Des. Dev., 1957, vol. 49, № 4, pp. 780-784.

15. Шапошник В. А., Васильева В. И., Григорчук О. В. //Электрохимия, 2006, т. 42, № 11, с. 13401345.

16. Vasil'eva V. I., Shaposhnik V. A., Grigorchuk O. V., Petrunya I. P. // Desalination, 2006, vol. 192, № 1-3, pp. 408-414.

17. Lopatkova G., Basova O., Volodina E., Pismenskaya N., Nikonenko V., Chaabane L., Cot D. "Environmental Problems and Ecological Safety”, Proceedings of the International Workshop, September - October 2004, Germany, pp. 145-153.

18. Салдадзе Г. К. Ионселективные мембраны и электромембранные процессы. М.: НИИТЭХим, 1986, $24 \mathrm{c.}$

19. Березина Н. П., Ивина О. П., Рубинина Д. В. Диагностика ионообменных мембран после реального электродиализа. Краснодар, Кубанский государственный университет, 1990, 11 с.

20. Салдадзе К. М., Климова 3. В., Титова Н. А., Базикова Г. Д. Ионообменные мембраны в электродиализе. Ленинград, Химия, 1970, 65 с.

21. Васильева В. И., Битюцкая Л. А., Зайченко Н. А., Гречкина М. В., Ботова Т. С., Агапов Б. Л. // Сорбиионные и хроматографические процессы, 2008, т. 8, № 2, c. 260-271.

22. Письменская Н. Д., Никоненко В. В., Мельник Н. А., Шевцова К. А. // Мембраны и мембранные технологии, 2011, т. 1, № 3, с. 201-212.

23. Васильева В. И., Акберова Э. М., Жильцова А. В., Черных Е. И., Сирота Е. А., Агапов Б. Л. // Поверхность. Рентгеновские, синхротронные и нейтронные исследования, 2013, № 9, с. 27-34. 
24. Акберова Э. М., Малыхин М. Д. // Сорбциионные и хроматографические прочессы, 2014, т. 14, вып. 2, c. 232-239.

25. Яцев А. М., Акберова Э. М., Голева Е. А., Васильева В. И., Малыхин М. Д. // Сорбционные и хроматографические прочессыл, 2017, т. 17, № 2, с. 313-322.

26. Васильева В. И., Письменская Н. Д., Акберова Э. М., Небавская К. А. // Журнал физической химии, 2014, т. 88, № 8, с. 1114-1120.

27. Васильева В. И., Акберова Э. М., Шапошник В. А., Малыхин М. Д. // Электрохимия, 2014, т. 50, № 8, c. 875-883.

28. Демина О. А., Березина Н. П., Сата Т., Демин А. В. // Электрохимия, 2002, т. 38, № 8, с. $1002-$ 1008.

29. Березина Н. П., Кононенко Н. А., Дворкина Г. А., Шельшедов Н. В. Физико-химические свойства ионооб- менных материалов. Краснодар, Кубанский государственный университет, 1999, 82 с.

30. Berezina N. P., Kononenko N. A., Dyomina O. A., Gnusin N. P. // Advances in Colloid and Interface Science, 2008, vol. 139, pp. 3-28.

31. Шапошник В. А., Емельянов Д. Е., Дробышева И. В. // Коллоидный журнал, 1984, т. 46, № 4, с. 820822.

32. Сирота Е. А., Кранина Н. А., Васильева В. И., Малыхин М. Д., Селеменев В. Ф. // Вестник ВГУ, Серия: Химия. Биология. Фармация, 2011, № 2, с. 53-59.

33. Васильева В. И., Жильцова А. В., Малыхин М. Д., Заболоцкий В. И., Лебедев К. А., Чермит Р. Х., Шарафан М. В. // Электрохимия, 2014, т. 50, № 2, с. 134-143.

34. Лурье Ю. Ю. Справочник по аналитической химии. М.: Альянс, 1989, 446 с.

35. Nagaaki T. // Journal of the Chemical Society of Japan, 1973, № 3, pp. 482.

\title{
MINERAL FOULING ON THE MA-40 ANION EXCHANGE MEMBRANE WITH THE AT ELECTRODIALYSIS OF STRONGLY MINERALIZED NATURAL WATERS
}

\author{
(C) 2017 E. M. Akberova, A. M. Yatsev, E. A. Goleva, V. I. Vasil'eva \\ Voronezh State University, 1Universitetskaya sq., 394018 Voronezh, Russia \\ e-mail: elmara_09@inbox.ru
}

Received 10.05.2017

\begin{abstract}
Mineral fouling of ion exchange membranes is one of the major problems during electrodialysis operation. The purpose of this work is the detection of the relationship between the structural and transport properties of the MA-40 anion exchange membrane after prolonged use desalinating and concentrating natural waters.

Structural changes of the MA-40 anion exchange membrane after continuous operation in electrodialysis stacks of various types are evaluated by scanning electron microscopy. The physicochemical characteristics of membranes were identified by the standard procedures. The conductivity was measured by the contact-difference method. The diffusion properties of the membranes were determined by estimating the amount of electrolyte, which was transported through the membrane to the water.

The influence of structural changes in the MA-40 anion-exchange membrane after the electrodialysis of natural waters on the physical-chemical and electrochemical characteristics were estimated. The possible mechanisms of decreasing the operational characteristics of MA-40 membranes, which arise due to the demineralization and concentrating of natural waters, were revealed via the electrodialysis method. The main cause of reduction of the transport properties of membranes from near-electrode sections from the reverse electrodialysis stack during demineralization of natural waters from the Aral region is precipitation occurring both on the membrane surface and in its bulk. If on the membrane surface $\mathrm{Mg}$ insoluble compounds are preferably formed, then in the membrane phase on both sides of the surface the formation of $\mathrm{CaCO}_{3}$ is established. The main reason for the deterioration of the operational characteristics of the MA-40 anion-exchange membrane after electrodialysis concentration of natural waters is the destruction of ionogenic groups of the membranes, which causes a decrease in the total exchange capacity. The increase in surface macroporosity was accompanied by a slight mineral scaling of a carbonate nature.
\end{abstract}

Keywords: anion-exchange membrane, reverse electrodialysis stack, electrodialyzer-concentrator, natural waters, mineral fouling. 


\section{ACKNOWLEDGMENTS}

The authors are grateful to the Director of JSC “Membrane Technologies”, Dr. Sci. (Techn.), laureate of the State Prize of the Kazakh SSR in the field of science and technology Tskhay A.A. for providing membrane samples for research.

Microphotographs of the membranes surface were obtained at the Voronezh State University Centre for Collective Use of Scientific Equipment.

This work was financially supported by RFBR grant (project No 15-08-05031).

\section{REFERENCES}

1. Mulder M. Introduction to Membrane Technology. Moscow, World Publ., 1999, 513 p. (in Russian)

2. Uilson Dzh. R. Demineralization by Electrodialysis Method. Moscow, Gosatomizdat Publ., 1963, 351 p. (in Russian)

3. Korngold E., de Kцrцsy F., Rahav R., Taboch M. F. Desalination, 1970, vol. 8, pp. 195-220. DOI: 10.1016/ S0011-9164(00)80230-1

4. Kastuchik A. S., Shaposhnik V. A. Sorption and Chromatographic Processes, 2009, vol. 9, no. 1, pp. 51-57. Available at: http://www.sorpchrom.vsu.ru/articles/ 20090104.pdf (in Russian).

5. Ivakina E. I., Shatalov A. Ya., Isayev N. I. Ion-exchange Membranes in Electrodialysis. Leningrad, Chemistry Publ., 1970, pp. 78-84. (in Russian)

6. Bobreshova O. V., Lapshina T. E., Shatalov A. Ya. Russ. J. Appl. Chem., 1980, vol. 53, no. 3, pp. 665-667. (in Russian)

7. Bobreshova O. V., Shatalov A. Ya. Russ. J. Phys. Chem., 1977, vol. 51, no. 1, pp. 203-204. (in Russian)

8. Shaposhnik V. A., Zubets N. N., Strygina I. P., Mill’ B. E. Russ. J. Appl. Chem., 2001, vol. 74, no. 10, pp. 1653-1657. DOI: 10.1023/A:1014896916981

9. Katz W. E., Desalination, 1979, vol. 28, pp. 31-40. DOI: 10.1016/S0011-9164(00)88124-2

10. Grebenyuk V. D., Strizhak M. P. Water Chemistry and Technology, 1985, vol. 7, no. 5, pp. 39-40. (in Russian)

11. Meyer K. H., Straus W. Helv. Chem. Acta, 1940, vol. 23, pp. 795-800. DOI: 10.1002/hlca.19400230199

12. Grebenyuk V. D., Mazo A. A. Water Desalination by Ion-exchangers. Moscow, Chemistry Publ., 1980, 256 p. (in Russian).

13. Gregor H. P., Bruins P. F., Rothenberg M. Ind. Eng. Chem. Process Des. Dev., 1965, vol. 4, no. 1, pp. 3-6. DOI: 10.1021/i260013a002

14. Rosenberg N. W., Tirrell C. E. Ind. Eng. Chem., 1957, vol. 49, no. 4, pp. 780-784. DOI: 10.1021/ ie50568a047

15. Shaposhnik V. A., Vasil'eva V. I., Grigorchuk O. V. Russ. J. Electrochem., 2006, vol. 42, no. 11, pp. 1202-1207. DOI: 10.1134/S1023193506110061 (in Russian)
16. Vasil'eva V. I., Shaposhnik V. A., Grigorchuk O. V., Petrunya I. P. Desalination, 2006, vol. 192, № 1-3, pp. 408414. DOI: 10.1016/j.desal.2005.06.055

17. Lopatkova G., Basova O., Volodina E., Pismenskaya N., Nikonenko V., Chaabane L., Cot D. "Environmental Problems and Ecological Safety", Proceedings of the International Workshop, September - October 2004, Germany, pp. 145-153.

18. Saldadze G. K. Ion-Selective Membranes and Electromembrane Processes. Moscow, NIITEKChim. Publ., 1986, pp. 18-24. (in Russian)

19. Berezina N. P., Ivina O. P., Rubinina D. V. Diagnosis of Ion-Exchange Membranes after Real Electrodialysis. Krasnodar, Kuban. Gos. Univ. Press., 1990, 11 p. (in Russian)

20. Saldadze K. M., Klimova S. V., Titova N. A., Bazikova G. D. Ion-Exchange Membranes in Electrodialysis. Leningrad, Chemistry Publ., 1970, 65 p. (in Russian)

21. Vasil'eva V. I., Bitjutskaya L. A., Zaychenko N. A., Grechkina M. V., Botova T. S., Agapov B. L. Sorption and Chromatographic Processes, 2008, vol. 8, no. 2, pp. 260271. Available at: http://www.sorpchrom.vsu.ru/articles/20080210.pdf (in Russian)

22. Pis'menskaya N. D., Nikonenko V. V., Mel'nik N. A., Shevtsova K. A., Dammak L., Larchet C. Petroleum Chemistry, 2011, vol. 51, iss. 8, pp. 610-619. DOI: 10.1134/ S0965544111080081. (in Russian).

23. Vasil'eva V. I., Akberova E. M., Zhiltsova A. V., Chernykh E. I., Sirota E. A., Agapov B. L. J. Surface Investigation. Xray, Synchrotron and Neutron Techniques, 2013, vol. 7, no. 5, pp. 833-840. DOI:10.1134/S102745 1013050194

24. Akberova E. M., Malykhin M. D. Sorption and Chromatographic Processes, 2014, vol. 14, no. 2, pp. 232 239. Available at: http://www.sorpchrom.vsu.ru/articles/20140207.pdf(in Russian)

25. Yatsev A. M., Akberova E. M., Goleva E. A., Vasil'eva V. I., Malykhin M. D. Sorption and chromatographic processes, 2017, vol. 17, no. 2, pp. 313-322. Available at: http://www.sorpchrom.vsu.ru/articles/20170219.pdf (in Russian)

26. Vasil'eva V. I., Pismenskaya N. D., Akberova E. M., Nebavskaya K. A. Russ. J. Phys. Chem. A, 2014, vol. 88, no. 8, pp. 1293-1299. DOI:10.1134/S0036024414080317

27. Vasil'eva V. I., Akberova E. M., Shaposhnik V. A., Malykhin M. D., Russ. J. Electrochem, 2014, vol. 50, pp. 789-797. DOI: 10.1134/S102319351408014X

28. Demina O. A., Berezina N. P., Sata T., Demin A. V. Russ. J. Electrochem, 2002, vol. 38, iss. 8, pp. 896-902. DOI: 10.1023/A:1016874014470

29. Berezina N. P., Kononenko N. A., Dvorkina G. A., Shel'shedov N. V. Physical-chemical Properties of IonExchange Materials. Krasnodar, Kuban. Gos. Univ. Publ., 1999, 82 p. (in Russian)

30. Berezina N. P., Kononenko N. A., Dyomina O. A., Gnusin N. P. Advances in Colloid and Interface Science, 2008, vol. 139, p. 3-28. DOI: 10.1016/j.cis.2008.01.002 
31. Shaposhnik V. A., Yemel’yanov D. E., Drobysheva I. V. Colloid Journal, 1984, vol. 46, no. 4, pp. 820-822. (in Russian)

32. Sirota E. A., Kranina N. A., Vasil'eva V. I., Malykhin M. D., Selemenev V. F. Proceedings of Voronezh State University. Series: Chemistry. Biology. Pharmacy, 2011, no. 2, pp. 53-59. Available at: http://www.vestnik.vsu.ru/ program/view/view.asp?sec=chembio\&year=2011\&num= 02\&f_name=2011-02-08 (in Russian)
33. Vasil'eva V. I., Zhil’tsova A. V., Malykhin M. D. Zabolotskii V. I., Lebedev K. A., Chermit R. Kh., Sharafan M. V. Russ. J. Electrochem., 2014, vol. 50, no. 2, pp. 120-128. DOI: 10.1134/S1023193514020062 (in Russian)

34. Lur’ye Yu. Yu. Handbook of Analytical Chemistry. Moscow, Alliance Publ., 1989, 446 p. (in Russian)

35. Nagaaki T. Journal of the Chemical Society of Japan, 1973, no. 3, p. 482.
Акберова Эльмара Маликовна - к. х. н., ведущий инженер кафедры аналитической химии, Воронежский государственный университет; e-mail; elmara_09@inbox.ru

Яцев Андрей Михайлович - магистрант химического факультета, Воронежский государственный университет; e-mail: yatsev-andrey@mail.ru

Голева Елена Алексеевна - старший лаборант кафедры аналитической химии, Воронежский государственный университет

Васильева Вера Ивановна - д. х. н., профессор кафедры аналитической химии, Воронежский государственный университет; e-mail: viv155@mail.ru
Akberova Elmara M. - Cand. Sci. (Chem.), Leading Engineer of theAnalytical Chemistry Department, Voronezh State University; e-mail: elmara_09@inbox.ru.

Yatsev Andrey M.- the competitor for science degree of Master Science in Chemistry of the Analytical Chemistry Department, Voronezh State University; e-mail: yatsevandrey@mail.ru

Goleva Elena A. - Senior Assistant of the Analytical Chemistry Department, Voronezh State University

Vasil'eva Vera I. - Dr. Sci. (Chem.), Professor of the Analytical Chemistry Department, Voronezh State University; e-mail: viv155@mail.ru 